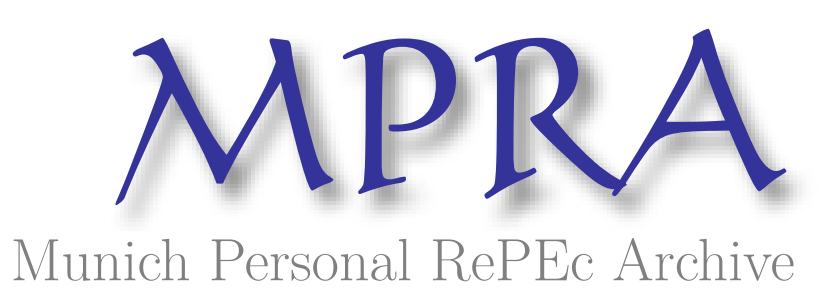

\title{
Financial liberalization and contagion with unobservable savings
}

Panetti, Ettore

1 March 2011

Online at https://mpra.ub.uni-muenchen.de/29540/

MPRA Paper No. 29540, posted 16 Mar 2011 11:59 UTC 


\title{
Financial Liberalization and Contagion with Unobservable Savings
}

\author{
Ettore Panetti \\ Institute for International Economic Studies* \\ March 1, 2011 \\ [Preliminary and incomplete]
}

\begin{abstract}
How do market-based channels for the provision of liquidity affect financial liberalization and contagion? In order to answer this question, I extend the Diamond and Dybvig (1983) model of financial intermediation to a two-country environment with unobservable markets for borrowing and lending and comparative advantages in the investment technologies. I demonstrate that the role of hidden markets crucially depends on the level of financial integration of the economy. Despite always imposing a burden on intermediaries, unobservable markets allow agents to partially enjoy gains from financial integration when interbank markets are autarkic. In fully liberalized systems such effect instead disappears. Similarly, in autarky the distortion created by hidden markets improve the resilience of the system to unexpected liquidity shocks. With fully integrated interbank markets, such effect again disappears, as unexpected liquidity shocks always lead to bankruptcy and contagion.
\end{abstract}

Keywords: Financial intermediation, liberalization, financial contagion, unobservable savings

JEL Classification: E44, G21, G28

${ }^{*}$ Contact details: Institute for International Economic Studies, Stockholm University, SE-106 91 Stockholm, Sweden. Email: ettore.panetti@iies.su.se. I would like to thank Per Krusell and John Hassler for their help at various stages of the project, and seminar participants at SUDSWEc 2010, IIES Macro Group and Stockholm School of Economics for helpful comments. 


\section{Introduction}

In the present paper, I address the following issue: how do market-based channels for the provision of liquidity affect financial liberalization and contagion? This is an important question in the current debate about financial intermediation, as in the last forty years there has been a "horse race" between two different systems: the "Anglo-Saxon", with its unregulated market-based structure and extensive financial innovation, and the "Continental European", traditionally bank-based. Such debate apparently settled at the end of the Nineties: both researchers in academia and policy makers in practice agreed that the first one was the way to go to ensure an efficient allocation of risk, and as a consequence foster financial and economic growth. The impetuous wave of financial liberalization across the world was just another effect of the general consensus about the issue. Nevertheless, the calamitous events of the 2007-2009 financial crisis reopened the discussion, as the European model showed more resilience to unexpected shocks and bank runs than the other. In fact, according to the latest data, ${ }^{1}$ the United States administration spent around US $\$ 2$ trillion in bailing out the financial system, and in Europe United Kingdom spent alone more than 900 million euros, which represent half of the total public intervention of the whole continent. As a counterexample, France, Italy and Spain, where a bank-based financial system is present, did not spend more than 100 million euros overall.

With the present paper, I give a theoretical contribution to this debate. I start from the standard workhorse model for normative and positive analysis of financial intermediation developed by Diamond and Dybvig (1983). In their model, financial intermediaries (or more commonly, banks) provide risk sharing against the realization of idiosyncratic liquidity shocks by offering maturity, liquidity and credit transformation. Banks ex ante collect deposits and make investments on behalf of their customers, and offer a contract that states how much agents are allowed to withdraw ex post, depending on their random preferences for liquidity. In order to study the interaction of different regulatory environments on financial liberalization and on the resilience of financial systems to unexpected liquidity shocks, I extend this model in two directions: first, I assume a two-sector (or region, or country) environment, in which banks enjoy a regulatory comparative advantage in the available investment technology; second, I study the role of market-based financial systems via the introduction of hidden borrowing and lending.

The reasons for such hypotheses deserve some explanations. On the one hand, I use the

\footnotetext{
${ }^{1}$ See the report by Mediobanca Research Department (2010) at http://www.mbres.it/eng/download/rs _main_financial_stabilization_plans.pdf.
} 
two-sector environment to analyze different institutional set-ups in the interbank market. I will compare different cases in which banks in one country either are or are not allowed to make deposits into banks in the other country, as a proxy for liberalized versus rigid financial systems. On the other hand, the introduction of an informational friction in the form of hidden savings is made to formally take into account the recent developments in financial innovation and the emergence of a series of unregulated markets, intermediaries and structures known as "shadow banking system". According to Pozsar et al. (2010), "shadow banks are financial intermediaries that conduct maturity, credit and liquidity transformation without access to central bank liquidity or public sector credit guarantees". No measure of the dimension of the shadow banking system existed until recently (current estimates argue the total amount of resources traded can be as large as US\$12 Trillion), as for their intimate essence the actions of such operators are difficult to track. Nevertheless, we can draw some evidence by taking total financial assets as a proxy for the dimension of such sector. ${ }^{2}$ Data show that for the shadow banking system such value grew from U.S.\$ 2.5 billion in the early Nineties to a peak of U.S. $\$ 24$ billion in 2007 . This tenfold growth is even more noteworthy if we take into account that total financial assets of traditional commercial banks have not increased at the same pace: in fact, while at the beginning of the Nineties the ratio of shadow banking to commercial banks' total assets was 52 percent, before the beginning of the financial crisis it peaked at 200 percent. From the point of view of the present work, the lesson I draw is therefore that a great part of the wealth in the United States has been conveyed in the economy through "off-the-counter" unobserved channels, hence the introduction of unobservable savings captures a fundamental feature of the current financial system that researchers cannot ignore.

In this environment, I am able to prove the following results. In competitive equilibrium, the presence of hidden markets always imposes a burden on financial intermediaries, who see their choice sets compressed by the necessary incentive compatibility. Nevertheless, hidden markets have different effects on the equilibrium outcome, depending on the level of integration in the "official" financial market: when international interbank markets are not developed, cross-country borrowing and lending, even if unobservable, do increase welfare with respect to the case of complete economic isolation, because in this way agents partially enjoy gains from financial integration. On the contrary, when international interbank markets are fully liberalized, hidden markets only have a negative effect: were hidden markets closed, the competitive equilibrium would indeed be equivalent to the social optimum.

\footnotetext{
${ }^{2}$ Data are taken from the Flow of Funds Accounts of the United States.
} 
On the other side, in order to study financial contagion I analyze the resilience of the financial system to a perturbation: I introduce the state $\bar{S}$, in which suddenly and unexpectedly the number of agents in early liquidity need increases. Were the economy divided into autarkic regions, I prove that international shadow markets would distort the optimal allocation of consumption towards late consumers, and push banks to specialize their investment strategies. That in turn is beneficial for the resilience of the system, since banks always have enough resources to cover for extra liquidity needs. That does not come at no cost, though: unexpected liquidity shocks would still produce winners and losers from the redistribution of resources via the hidden market.

When the interbank market is opened, the positive stabilizing effect of hidden markets instead disappears, as banks do trade internationally and therefore do not specialize in liquid assets. Therefore, banks always go bankrupt, and there is always contagion. The introduction of optimal regulation, to overcome the inefficient allocation of resources in competitive equilibrium, in fact does not solve the instability of the system, as banks are forced to hold less long assets and therefore lower the buffers with which they might cover the extra liquidity needs. Therefore, my conclusion is again that the role of hidden markets in the development of financial contagion crucially depends on the underlying structure of the interbank market.

The present paper contributes to different topics in the literature. In general, it belongs to a wide and revamping line of research on financial intermediation, which has in the already mentioned work by Diamond and Dybvig (1983) its cornerstone. In particular, it embraces the "business cycle" view about the origin of financial crises, which has in Gorton (1988) its first and most important contributor. According to that view, financial crises are not the outcome of self-fulfilling prophecies, as in the standard Diamond-Dybvig model, but are consequences of real shocks affecting the economy, that is, an equilibrium outcome. In addition to that, my paper is also related to the literature that rationalizes international transmission of financial shocks through interbank channels, like in Allen and Gale (2000) or Brusco and Castiglionesi (2007). The importance of such approach has been further strengthened by recent empirical analysis of default and contagion in networks of banks (Iyer and Peydró, 2010; Imai and Takarabe, 2011).

More importantly, the present work represents an extension of the analysis on hidden savings and financial intermediation proposed by Farhi et al. (2009). In particular, the authors highlight the distortion that hidden markets for borrowing and lending impose on the banking contract in decentralized environments. By extending their set-up to a two- 
country environment, I am able to further analyze how such distortion affects financial liberalization and the resilience of the system to unexpected liquidity shocks.

The paper is organized as follows: in sections 2 to 4 , I define the environment of the problem, characterize the socially optimal allocation and the decentralized equilibrium both with autarkic and liberalized interbank markets. Section 5 is devoted to the analysis of financial contagion. In section 6 I further show how the proposed analysis sheds some light on the crisis of the U.S. banking system between the end of the Seventies and the beginning of the Nineties (the so-called "S\&L debacle"). Section 7 concludes.

\section{Environment}

The basic structure of the model is a standard Diamond and Dybvig (1983) model of financial intermediation. The economy lasts for three periods $t=0,1,2$, and is divided into two countries (or sectors) $i \in\{H, F\}$. Each country is populated by $\mu^{i}$ ex ante identical agents, with $\mu^{H}+\mu^{F}=1$, who are born at date 0 with an equal endowment $e=1$, and by a continuum of Bertrand-competitive financial intermediaries (or more commonly, banks), who operate in an official market with free entry, and offer real deposit contracts to individuals. I assume the relationship between customers and banks is exclusive, in the sense that agents can only deposit their endowment into banks in their own sector. There are four assets available in the economy: two short assets, which are essentially a storage technology that yield one unit of consumption good in $t+1$ for each unit invested in $t$, and two country-specific long assets, which deliver $\hat{R}^{F}>\hat{R}^{H}>1$ units of consumption in period $t=2$ for each unit invested in $t=0$. In this respect, the short asset is "liquid", as it provides a way to move resources from one period to the following, while the long asset is "illiquid", as it has a longer maturity. In the design of the assumption that $\hat{R}^{F}>\hat{R}^{H}$, I have in mind a situation in which different parts of a composite financial system have different regulatory environments, and hence different technologies to move resources across time. In that sense, I define this hypothesis a "regulatory comparative advantage".

Agents are affected by idiosyncratic uncertainty, in the form of a preference shock. Being ex-ante equal, in $t=1$ every consumer draws a type $\theta \in\{0,1\}$ which is private information to herself. Individual types affect the point in time at which agents enjoy consumption, according to the utility function $U\left(c_{1}^{i}, c_{2}^{i}, \theta\right)=(1-\theta) u\left(c_{1}^{i}\right)+\beta \theta u\left(c_{2}^{i}\right)$. Clearly, if $\theta=0$ the agent is willing to consume only at date 1 , while if $\theta=1$ she will consume only at date 2. As it is customary in this line of research, I will then refer to type-0 and type-1 
agents as early and late consumers, respectively. The felicity function $u(c)$ is assumed to be increasing, twice continuously differentiable, concave, and satisfying Inada conditions. Moreover I restrict my attention to the class of felicity functions characterized by relative risk aversion bigger than or equal to unity, that is $-\frac{u^{\prime \prime}(c) c}{u^{\prime}(c)} \geq 1$, and assume throughout the rest of the paper that $\beta \hat{R}^{H}>1$.

Finally, define the probability of being of type $\theta$ in sector $i$ as $\pi^{i}(\theta)>0$. I assume that preference shocks are independent across agents, so that by the law of large number the cross-sectional distribution of types is equivalent to the probability distribution. Moreover, it must be that $\sum_{\theta} \pi^{i}(\theta)=\mu^{i}$ in any sector.

\subsection{The Banking Contract}

At the beginning of date 0 , agents deposit their endowments in banks in their own country, and sign a banking contract. This stipulates the amount of consumption goods that customers are entitled to withdraw from their banks at date 1 and 2, depending on their types. Define the consumption bundle $C^{i}(\theta)=\left\{c_{1}^{i}(\theta), c_{2}^{i}(\theta)\right\}$.

Once collected all the deposits, banks decide how to allocate them. Specifically, they may buy an amount $X^{i}$ of short assets, and an amount $Y^{i}$ of long assets. The structure of such markets is exogenous, and reflects two different institutional environments: in the first one, banks are in autarky, and can only invest in assets available in their own country; in the second, they are instead allowed to make deposits into banks in other sectors, and ask them to invest in short or long assets on their behalf. I will then call the first environment "autarkic" and the second one "liberalized" or "integrated".

Notice that in the following I focus my attention on pure strategy equilibria, where banks in the same group have symmetric investment strategies. Therefore, without loss of generality I can restrict myself to the analysis of a representative bank.

\subsection{The Shadow Market}

The second market in this economy opens at $t=1$, after all the uncertainty is realized, when agents have the opportunity to engage in side trades. I model this feature as unobservable exchanges, through which individuals can freely borrow and lend across countries an amount $b^{i}$ of uncontingent bonds yielding a "shadow return" $R$ to be determined in equilibrium. Notice that, despite the fact that agents can only deposit their endowment in banks in their own country, I allow them to directly trade at a later stage. Moreover, 
the fact that agents trade only uncontingent bonds is not an a priori restriction on the completeness of the hidden market, but an endogenous feature of the hidden market. I prove that in appendix A. ${ }^{3}$

I formalize the problem faced by the agents in the shadow market in the following way. Individuals take their decisions to borrow or lend at the end of date 1. State variables of the program are the banking contract $C^{i}(\theta)$ signed in the official banking sector, the shadow return $R$ that emerges in equilibrium, and the individual type. Then, the problem in the shadow market reads:

$$
\begin{array}{cc}
V\left(C^{i}(\theta), R, \theta\right)= & \max _{x_{1}^{i}, x_{2}^{i}, b^{i}, \theta^{\prime}} U\left(x_{1}^{i}, x_{2}^{i}, \theta\right) \\
\text { s.t. } & x_{1}^{i}+b^{i}=c_{1}^{i}\left(\theta^{\prime}\right) \\
& x_{2}^{i}-R b^{i}=c_{2}^{i}\left(\theta^{\prime}\right)
\end{array}
$$

Given the state variables, individuals decide which type $\theta^{\prime}$ to report to the official sector (which will affect the amount of resources available for side trades), how much to consume in the two periods, and how much to borrow or lend in the shadow market.

So far the environment describes a complex game of asymmetric information between banks and depositors. Nevertheless, by the Revelation Principle I can focus my attention to truth-telling mechanisms in which agents have incentives to reveal their individual types to the banks. The incentive compatibility constraint can then be defined in the following way:

Definition 1. A banking contract $C^{i}(\theta)$ is incentive compatible if:

$$
V\left(C^{i}(\theta), R, \theta\right) \geq V\left(C^{i}\left(\theta^{\prime}\right), R, \theta\right)
$$

for any $\theta, \theta^{\prime} \in\{0,1\}$.

Incentive compatibility states that each agent should find optimal to truthfully report her type, but given the presence of only two types, this can be simplified:

\footnotetext{
${ }^{3}$ I could have modeled the shadow market so that agents were allowed to write side contracts with financial institutions in other sectors. Instead, I follow Farhi et al. (2009) and assume that they trade only with other individuals. That would not change the main implications of the paper, while consistently simplifying the analysis.
} 
Lemma 1. A banking contract $C^{i}(\theta)$ is incentive compatible if:

$$
c_{1}^{i}(0)+\frac{c_{2}^{i}(0)}{R}=c_{1}^{i}(1)+\frac{c_{2}^{i}(1)}{R}
$$

Proof. In Appendix D.

Truth-telling therefore implies that the banking contract should entitle agents to the same present discounted value of consumption, evaluated at the return on the shadow investment.

\subsection{Timing}

It is useful at this point to summarize the timing of actions: at date 0, each agent deposits her endowment into banks in her own country, hence total deposits are $\mu^{i}$. Banks then set up full contingent incentive-compatible contracts with depositors, entitling them to an amount of real consumption at date 1 and 2, depending on the reported type. Banks also decide the portfolio allocation between long and short assets. At $t=1$, all uncertainty is resolved: each agent gets to know her private type, and according to the report they make to the bank receives consumption goods $c_{1}^{i}(\theta)$. Once having withdrawn, agents induce in side trades in the hidden market. Finally, at $t=2$ individuals receive consumption goods $c_{2}^{i}(\theta)$ in accordance with the banking contract, and the return on the shadow investment.

\section{Constrained Efficient Allocation}

As a benchmark case, in this section I characterize the socially optimal allocation. In particular, the planner chooses the optimal contract $\left\{C^{i}(\theta)\right\}$ for any consumer in the economy and the efficient portfolio allocation between short and long assets in order to maximize the sum of expected ex-ante welfare. In doing so, the planner is subject to the constraint that the portfolio allocation must provide enough resources to pay consumption in both periods to any agent of any type. In addition, remember that individual types are private information. We can then apply the Revelation Principle and restrict the social planner to truth-telling mechanisms in which every agent correctly report her type and does not trade in the hidden market. The planning problem reads:

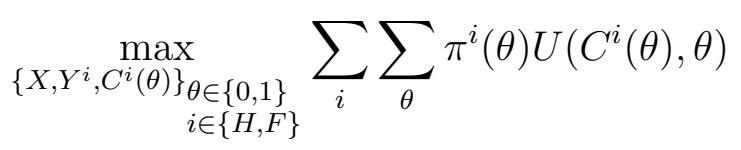


subject to the resource constraints:

$$
\begin{aligned}
X+Y^{H}+Y^{F} & =1 \\
\sum_{i} \sum_{\theta} \pi^{i}(\theta) c_{1}^{i}(\theta) & \leq X \\
\sum_{i} \sum_{\theta} \pi^{i}(\theta) c_{2}^{i}(\theta) & \leq \hat{R}^{H} Y^{H}+\hat{R}^{F} Y^{F}
\end{aligned}
$$

and the incentive compatibility constraint:

$$
U\left(C^{i}(\theta), \theta\right) \geq V\left(C^{i}(\theta), R, \theta\right)
$$

which must hold for any type and any sector.

Notice that, given that the investment in the short assets in both $\mathrm{H}$ and $\mathrm{F}$ yields the same return, I define as $X$ the total investment in the short asset. On the contrary, $Y^{H}$ and $Y^{F}$ are the investments in the long assets of $\mathrm{H}$ and F. Since by assumption $\hat{R}^{F}>\hat{R}^{H}$, the planner will optimally invest only in F's long asset. I report the full definition of the constrained efficient allocation in the Appendix. Moreover, I also prove that the program can be simplified along the lines proposed by Farhi et al. (2009). The constrained efficient allocation is characterized in the following lemma:

Lemma 2. The constrained efficient allocation in presence of hidden markets is:

$$
\begin{aligned}
& c_{1}^{i}(1)=c_{2}^{i}(0)=0 \\
& c_{1}^{i}(0)=\mathcal{I}^{*}>1 \\
& c_{2}^{i}(1)=R^{*} \mathcal{I}^{*}<\hat{R}^{F}
\end{aligned}
$$

for any $i \in\{H, F\}$, where $\left\{R^{*}, \mathcal{I}^{*}\right\}$ is the solution to:

$$
\begin{gathered}
\frac{u^{\prime}\left(\mathcal{I}^{H *}\right)}{u^{\prime}\left(\mathcal{I}^{F *}\right)}=1=\frac{u^{\prime}\left(R^{*} \mathcal{I}^{H *}\right)}{u^{\prime}\left(R^{*} \mathcal{I}^{F *}\right)} \\
\beta \hat{R}^{F} u^{\prime}\left(R^{*} \mathcal{I}^{*}\right)=u^{\prime}\left(\mathcal{I}^{*}\right) \\
\sum_{i} \mathcal{I}^{*}\left[\pi^{i}(0)+\frac{R^{*}}{\hat{R}^{F}} \pi^{i}(1)\right]=1
\end{gathered}
$$


Moreover, the efficient return in the shadow market is:

$$
1<R^{*} \leq \beta \hat{R}^{F}<\hat{R}^{F}
$$

and the optimal total investment in the short asset is:

$$
X^{*}=\sum_{i} \pi^{i}(0) \mathcal{I}^{*}
$$

Proof. In appendix D.

The planner optimally does not provide any consumption at date 1 to late consumers, and at date 2 to early consumers. She chooses the allocation of resources so as to implement cross-country risk sharing (i.e. she provides the same consumption regardless of the country) and intertemporal risk sharing (i.e. she ensures an ex-ante Eurler equation holds). The effect of that is a reduction in ex-post income volatility $\left(c_{1}^{i}(0)>1\right.$ and $\left.c_{2}^{i}(1)<\hat{R}^{F}\right)$ : the planner ensures agents against the risk of being hit by a liquidity shock by pooling deposits and shifting resources from late consumers to early consumers.

Furthermore, the planner also needs to satisfy incentive compatibility, and she does so by ensuring that the return on the shadow market is strictly lower than the return on the chosen long asset $\hat{R}^{F}$, so as to lower incentives to misreport individual types. For the sake of clarity, assume utility is CRRA. Then by rearranging the Euler equation, we have $R^{*}=\left(\beta \hat{R}^{F}\right)^{\frac{1}{\sigma}}$ : the optimal return on the hidden investment reflects consumption smoothing motivations, i.e. the willingness of agents to hedge against idiosyncratic liquidity shocks. The higher relative risk aversion $\sigma$, the more agents want a smooth consumption profile. Therefore, in order for incentive compatibility to hold, the hidden return $R^{*}$ should get closer to unity.

Finally, it is easy to see that in this environment the constrained efficient allocation is equivalent to the unconstrained efficient one: they both provide efficient cross-country and iter-temporal risk sharing, while exhausting resources. Moreover, in the same environment with no hidden trades, a version of the first welfare theorem holds: the competitive equilibrium is equivalent to the social optimum. This result was proved in a more general set-up by Allen and Gale (2004). I provide some intuition for that in Appendix B. 


\section{Competitive Equilibrium}

In this section, I define and characterize the market equilibrium of the environment described in the previous section. I solve for the consumption allocation and the portfolio strategy by backward induction, where the first stage is represented by the savings problem (1) that each agent solves in the hidden market.

At date 0 , then banks choose the optimal investment strategy and the banking contract so as to maximize expected ex post utility: ${ }^{4}$

$$
\sum_{\theta} \pi^{i}(\theta) V\left(C^{i}(\theta), R, \theta\right)
$$

subject to incentive compatibility (3) and the budget constraint. The structure of the interbank market affects the latter, in particular which long asset banks can invest into. In the following, I concentrate my attention on three different cases. In the first one, no international transaction is possible: there is no interbank market, and the shadow market is limited to be domestic. In the second one, banks are still forbidden from making deposits one into each other, but agents can exchange resources in a international hidden market. Finally, in the third case, there exist both an international interbank market and a crosscountry shadow market. I will show how different degrees of openness affect how shadow markets influence the economic outcome.

\subsection{Autarky with Domestic Hidden Markets}

In this first institutional set-up, there are no international markets: banks are not allowed to trade in an interbank market, and the hidden market for borrowing and lending is constrained to be only local. The budget constraint in each country $i$ then is:

$$
\begin{aligned}
X^{i}+Y^{i} & \leq \mu^{i} \\
\sum_{\theta} \pi^{i}(\theta) c_{1}^{i}(\theta) & \leq X^{i} \\
\sum_{\theta} \pi^{i}(\theta) c_{2}^{i}(\theta) & \leq \hat{R}^{i} Y^{i}
\end{aligned}
$$

\footnotetext{
${ }^{4}$ The assumption of Bertrand competition among banks drives profits to zero in equilibrium and lets me focus on the dual problem.
} 
Notice that each country is forced to invest in the domestic long assets, whose return is $\hat{R}^{i}$. The definition of competitive equilibrium is straightforward:

Definition 2. Given an initial endowment $e$ for any agent and a distribution of idiosyncratic shocks $\left\{\pi^{i}(\theta)\right\}$, a competitive equilibrium in autarky is a vector of hidden returns $\left\{R^{i A}\right\}$ on the two local shadow markets, ${ }^{5}$ a banking contract $\left\{C^{i}(\theta)\right\}$, a portfolio allocation $\left\{X^{i}, Y^{i}\right\}$ and an amount of bonds $b^{i}\left(C^{i}(\theta), R, \theta\right)$ for any country $i \in\{H, F\}$ and type $\theta \in\{0,1\}$, such that:

- For given return $R^{i A}$, the allocation solves the problem in the shadow market

- The allocation solves the banking problem

- Resources are exhausted:

$$
\begin{gathered}
\sum_{\theta} \pi^{i}(\theta)\left[c_{1}^{i}(\theta)+\frac{c_{2}^{i}(\theta)}{\hat{R}^{i}}\right]=\mu^{i} \quad \forall i \in\{H, F\} \\
\sum_{\theta} \pi^{i}(\theta) b^{i}\left(C^{i}(\theta), R^{i A}, \theta\right)=0
\end{gathered}
$$

In the definition of the equilibrium, I am assuming that resources must be exhausted in each country, and the shadow market must clear locally.

To find the solution to the program, I follow these steps: first, characterize the return on the shadow investment; second, solve agents' optimal strategy in the shadow market, for given banking contract; third, solve for the optimal banking contract. The first task is intuitive: the return on investments in each shadow market must be equal to the return to the local investment technology, i.e. $R^{i A}=\hat{R}^{i}$. The intuition for this result is straightforward. There are two ways banks can provide consumption to late consumers, and by the assumption of perfect competition they must be equivalent. They can invest one unit of consumption at date 0 in the long asset, and get $\hat{R}^{i}$ at date 2 , or they can invest one unit of consumption in the short asset, collect one at date 1, and give it to the consumers for them to invest in the shadow market, whose return is $R^{i A}$. Therefore, the result follows. ${ }^{6}$

Lemma 3. In an autarkic competitive equilibrium with domestic hidden markets, $R^{i A}=\hat{R}^{i}$.

\footnotetext{
${ }^{5}$ The superscript A stands for "autarky".

${ }^{6}$ There is a third way for banks to provide consumption to late consumers: invest twice in the short asset, at dates 0 and 1 . This strategy would yield one unit of consumption for each unit invested, hence is dominated by the other two.
} 
Proof. In the text above.

The main consequence of such lemma is that the portfolio allocation between short and long assets is not determined. Despite indeterminacy, I am still able to back up the optimal banking contract, though. Banks in both sectors find inefficient to provide consumption to late consumers at date 1 and to early consumers at date 2 , because that would be costly but not give any welfare to consumers. That in turn implies $c_{1}^{i}(0)=c_{2}^{i}(1) / R^{i A}$ by incentive compatibility. Then the resource constraint gives the equilibrium allocation, and as a consequence the equilibrium investment strategy, that I summarize here:

Proposition 1. The autarkic competitive equilibrium with domestic hidden markets is characterized by the optimal banking contract:

$$
\begin{aligned}
& c_{2}^{i}(0)=c_{1}^{i}(1)=0 \\
& c_{1}^{i}(0)=1 \\
& c_{2}^{i}(1)=\hat{R}^{i}
\end{aligned}
$$

and the equilibrium investment strategy is:

$$
\begin{aligned}
& X^{i}=\pi^{i}(0) \\
& Y^{i}=\mu^{i}-\pi^{i}(0)
\end{aligned}
$$

for any $i \in\{H, F\}$,

Proof. In the text above.

The intuition for such result is the following: banks are forced to implement an incentive compatible contract. But the return on the hidden market does not reflect the willingness of agents to hedge against idiosyncratic shocks as in the planner problem, but only arbitrage conditions between the observable and the unobservable markets. Therefore, this competitive equilibrium is highly inefficient: clearly, it does not provide any cross-country risk sharing, as late consumers are entitled to different amounts of consumption in the two different countries. Moreover, such equilibrium does not ensure any intertemporal risk sharing, too: an ex ante Euler equation here does not hold. This is an adapted version of a more general result that arises in models with hidden trades: in a competitive equilibrium, agents are not able to get more insurance than the one they might get if they were in 
complete autarky (i.e. if no bank was present). ${ }^{7}$

\subsection{Autarky with International Hidden Markets}

In this second case, banks are still not allowed to make cross-borders deposits. At the same time, countries are not isolated: agents can now operate in an international hidden market for borrowing and lending. Banks' budget constraint in each country $i$ is exactly the same as before, and also the definition of competitive equilibrium is similar to the previous case, with two exceptions: now there is only one return on the hidden investment labeled $R^{A}$, and I impose that in equilibrium the hidden market for bonds must clear internationally:

$$
\sum_{i} \sum_{\theta} \pi^{i}(\theta) b^{i}\left(C^{i}(\theta), R^{A}, \theta\right)=0
$$

I follow the same steps as before to characterize the solution, hence I start from the return to the hidden investment $R^{A}$. This must lie between $\hat{R}^{H}$ and $\hat{R}^{F}$. Were it lower than $\hat{R}^{H}$, banks in both sectors would find convenient to invest only in their own long assets and let depositors trade on the shadow market. But if that is the case, early consumers in both sectors would not be able to borrow on the shadow market, because there would be no lenders. Therefore, (14) is not satisfied, and that cannot be an equilibrium. Similarly, it cannot be the case that $R^{A}$ is bigger than $\hat{R}^{F}$, because otherwise banks would invest only in the short assets, and late consumers would not find anyone to lend to in the shadow market. I recap this in the following lemma:

Lemma 4. In an autarkic competitive equilibrium with international hidden markets, $\hat{R}^{H}<R^{A}<\hat{R}^{F}$.

Proof. In the text above.

\footnotetext{
${ }^{7}$ If there are no banks, each individual directly buys short and long assets. Assume that when she gets to know her type, each agent then sells at price $P$ the security that does not need on a secondary market. More formally:$$
\max _{X, Y} \quad \theta u\left(c_{1}\right)+\beta(1-\theta) u\left(c_{2}\right)
$$

subject to $X+Y=1$ and:

$$
X+P Y=c_{1} \quad ; \quad \hat{R}\left(\frac{X}{P}+Y\right)=c_{2}
$$

Since there must be no arbitrage opportunities between investing in short and long assets, in equilibrium it must be the case that $P=1$. Then from the budget constraint the consumption allocation is: $c_{1}=1$ and $c_{2}=\hat{R}$.
} 
Given the result above, it is then clear that banks in $\mathrm{H}$ find optimal to invest only in the short technology, and let late consumers lend in the shadow market so that they enjoy a higher return. On the contrary banks in F invest only in the long technology, and let domestic early consumers borrow. Given this result, I can rewrite the market clearing condition in the hidden bond market as:

$$
\pi^{H}(1) c_{1}^{H}(1)=\pi^{F}(0) \frac{c_{2}^{F}(0)}{R^{A}}
$$

That means the total amount lent by H's late consumers (the left hand side) in equilibrium must be equal to the total amount borrowed by F's early consumers (the right hand side). Equation (19) also points out that the existence of an equilibrium in the shadow banking system is dependent on the availability of the right number of borrowers and lenders. Thus, the existence of the equilibrium is ensured by the mild assumption:

Assumption 1. $\frac{\hat{R}^{H}}{\hat{R}^{F}}<\frac{\pi^{F}(0)}{\pi^{H}(1)}<1$

Given the market clearing condition in the bond hidden market, ex-post welfare is:

$$
\begin{aligned}
& V^{H}\left(C^{H}(0), R^{A}, 0\right)=u\left(c_{1}^{H}(0)\right) \\
& V^{H}\left(C^{H}(1), R^{A}, 1\right)=\beta u\left(R^{A} c_{1}^{H}(1)\right) \\
& V^{F}\left(C^{F}(0), R^{A}, 0\right)=u\left(\frac{c_{2}^{F}(0)}{R^{A}}\right) \\
& V^{F}\left(C^{F}(1), R^{A}, 1\right)=\beta u\left(c_{2}^{F}(1)\right)
\end{aligned}
$$

With those in hand, I can finally characterize the autarkic equilibrium:

Proposition 2. In autarkic competitive equilibrium with international hidden markets, the banking contract is:

$$
\begin{aligned}
& c_{2}^{H}(0)=c_{2}^{H}(1)=c_{1}^{F}(0)=c_{1}^{F}(1)=0 \\
& c_{1}^{H}(0)=c_{1}^{H}(1)=1 \\
& c_{2}^{F}(0)=c_{2}^{F}(1)=\hat{R}^{F}
\end{aligned}
$$

and the equilibrium investment strategy is:

$$
\begin{aligned}
& X^{H}=Y^{F}=1 \\
& X^{F}=Y^{H}=0
\end{aligned}
$$


The return on the shadow market is:

$$
R^{A}=\frac{\pi^{F}(0)}{\pi^{H}(1)} \hat{R}^{F}
$$

Proof. In appendix D.

The intuition for this result is straightforward: banks in each sector specialize their investments in those assets in which they enjoy their regulatory comparative advantage, and let agents trade in the shadow market to achieve maximum possible welfare. The important step at this point is to analyze the amount of risk sharing provided by bank in this environment. In order to do so, remember that the banking contract and the consumption allocation are different, because of the presence of the shadow market. Nevertheless, from the expressions for ex-post welfare it is easy to back up consumption bundles as:

$$
\begin{aligned}
x_{1}^{H}(0) & =1 & x_{2}^{H}(1) & =\frac{\pi^{F}(0)}{\pi^{H}(1)} \hat{R}^{F} \\
x_{1}^{F}(0) & =\frac{\pi^{H}(1)}{\pi^{F}(0)} & x_{2}^{F}(1) & =\hat{R}^{F}
\end{aligned}
$$

From this, it is clear that both cross-country and intertemporal risk sharing are not provided in this case, too.

It is important at this point to compare these first two cases: in autarky, irrespective of the presence of international hidden markets, banks are not able to provide insurance against idiosyncratic shocks or hedge against the ex ante heterogeneity represented by the country structure of the economy. Nevertheless, hidden markets allow agents to partially enjoy gains from financial integration, and that is the reason why the equilibrium with international hidden markets Pareto-dominates the one with local hidden markets. This conclusion will change when I take into account financial integration.

\subsection{Liberalized Economy with International Hidden Markets}

In contrast to what happens in autarky, in this last case I assume that banks are allowed to make cross-country deposits. In that sense, banks offer to their customers financial products that are not their own, through the channel of interbank trade. Formally, given that $\hat{R}^{H}<\hat{R}^{F}$, banks in $\mathrm{H}$ will not invest in their own long asset, but make deposits into banks in $\mathrm{F}$ and ask them to invest in the long assets on their behalf. The returns on the two short technologies available in the economy are equal, but without loss of generality I 
assume that banks in $\mathrm{F}$ will make deposits into banks in $\mathrm{H}$ and invest in the foreign short asset. ${ }^{8}$ Therefore, the intertemporal budget constraint of a bank in country $i$ now is:

$$
\sum_{\theta} \pi^{\theta}\left[c_{1}^{i}(\theta)+\frac{c_{2}^{i}(\theta)}{\hat{R}^{F}}\right]=\mu^{i}
$$

Notice that here banks in both countries discount date 2 consumption using the return on the long asset $\hat{R}^{F}$.

Formally, the definition of integrated equilibrium is not different from the previous one. The only exception is the resource constraint. Now, given that markets are liberalized and banks are free to make interbank deposits, it reads:

$$
\sum_{i} \sum_{\theta} \pi^{i}(\theta)\left[c_{1}^{i}(\theta)+\frac{c_{2}^{i}(\theta)}{\hat{R}^{F}}\right] \leq 1
$$

because resources must be exhausted in the whole economy.

Again, the characterization of the equilibrium starts from the derivation of the return in the shadow market. As before, I use arbitrage motivation to show that the hidden return $R^{L}$ must be equal to $\hat{R}^{F}$ : were it lower, banks in both sectors would only invest in the long asset, and early consumers would be willing to borrow, but they would not find any lender. Symmetric line of reasoning rules out the case in which $R^{L}>\hat{R}^{F}$.

Lemma 5. In integrated equilibrium, the return on the shadow market is $R^{L}=\hat{R}^{F}$.

Proof. In the text above.

As in the case with domestic hidden markets, consequence of this lemma is that the portfolio allocation between short and long asset is undetermined. The same lines of reasoning as before lead me to the characterization of the equilibrium consumption allocation:

Proposition 3. The integrated equilibrium is characterized by the optimal banking contract:

$$
\begin{aligned}
& c_{2}^{i}(0)=c_{1}^{i}(1)=0 \\
& c_{1}^{i}(0)=1 \\
& c_{2}^{i}(1)=\hat{R}^{F}
\end{aligned}
$$

\footnotetext{
${ }^{8} \mathrm{I}$ could formalize this point by assuming that the return on the short technology in country $\mathrm{H}$ is a small $\epsilon>1$, but that would just add to the notation.
} 
and the portfolio allocation:

$$
\begin{aligned}
& X^{i}=\pi^{i}(0) \\
& Y^{i}=\mu^{i}-\pi^{i}(0)
\end{aligned}
$$

for any $i \in\{H, F\}$,

Proof. In the text above.

Given this result about the optimal contract, and the fact that banks do know the probability distribution of idiosyncratic shocks, I can show that the total investment in the short asset in equilibrium is $X^{L}=\sum_{i} \pi^{i}(0)$, and as a consequence total investment in the long asset is $Y^{L}=1-X^{L}$ : total asset allocation in this economy is inefficient, as banks are too leveraged, i.e. do not invest enough in liquidity. Moreover, I can prove that intertemporal allocation is not satisfied either: the Euler equation does not hold. On the contrary, in the integrated equilibrium banks offer the same contract regardless of countries because they invest in the very same assets. Thus, they provide optimal cross-country risk sharing.

\subsection{Summary}

It is important at this point, to review my main findings so far. The presence of hidden markets always imposes a burden on financial intermediaries, who see their choice sets compressed by the necessary incentive compatibility. Nevertheless, hidden markets have different effects on the equilibrium outcome, depending on the market environment: when interbank markets are not developed, cross-country borrowing and lending, even if unobservable, do increase welfare with respect to the case of complete economic isolation, because in this way agents may partially enjoy gains from financial integration. On the contrary, when international interbank markets are into place, hidden markets only have a negative effect: as I mentioned in section 3, were hidden markets closed, the competitive equilibrium would indeed be equivalent to the social optimum.

In the next section, I will repeat the comparison between the three proposed environments, but to answer a new question: do hidden markets affect the resilience of the financial system to unexpected liquidity shocks? 


\section{Financial Contagion}

In the present section, I analyze how the presence of hidden markets affects bankruptcy and financial contagion. To do so, I take as a starting point the seminal work by Allen and Gale (2000). Notice that I explicitly focus my attention only on intrinsic default, i.e. default that has its origin in fundamental characteristics of the economy. This is in contrast with the literature that tries to explain bankruptcy as a consequence of self-fulfilling bank runs dependent on the realization of extrinsic events like sunspots.

Assume at date 1 state $\bar{S}$ is realized, in which suddenly and unexpectedly the number of agents in early liquidity need in country $\mathrm{H}$ spikes up to $\pi^{H}(0)+\epsilon$, and as a consequence the probability of being an early consumers decreases to $\pi^{H}(1)-\epsilon$. By the fact that the state $\bar{S}$ was not foreseen by intermediaries at date 0 , the banking contract is still equal to the one characterized in the previous sections. In order to fulfill the extra demand of liquidity, in state $\bar{S}$ banks might be forced to liquidate part of their holdings of the long asset before maturity. That comes at a cost: for any unit liquidated, banks raise only $r<1$ units of consumption via a liquidation technology. In state $\bar{S}$ then three cases are possible: banks are solvent, when they have enough resources (in terms of available liquidity) to pay for the extra demand; banks are insolvent, when they are forced to liquidate some of their holdings of the long asset; banks are bankrupt, when they are not able to fulfill their contractual obligations even by liquidating their whole portfolios. In case of bankruptcy, I assume banks are forced to sell all their assets and equally divide the proceedings among all their depositors. Therefore, in the following I address the role of hidden markets in inducing bankruptcy in $\mathrm{H}$ when the state $\bar{S}$ is realized, and ask whether the network of interbank deposits (if any) in turn induces bankruptcy also in F, in which case I talk about "contagion".

In the distinction mentioned above between the three possible cases (solvency, insolvency, bankruptcy), I implicitly assume there is a so called pecking order with which banks liquidate their assets to fulfill the demand for consumption in period 1 . The fact that banks first use the short asset and only afterwards the long asset is an endogenous feature of this set-up. Each asset indeed has different opportunity-cost of shifting consumption from date 2 to date 1. Such cost for the short asset is clearly equal to 1. For the long asset instead it is different: by liquidating one unit, banks get rid of $\hat{R}^{i}$ units of future consumption to create $r$ units of consumption at date 1 . Hence, the cost of shifting resources from 2 to 1 is $\hat{R}^{i} / r>1$, and that is the reason why banks use the short asset first. 


\subsection{The General Case}

I now summarize the main features of the model, as defined in Allen and Gale (2000). When state $\bar{S}$ materializes, banks in $\mathrm{H}$ face an extra demand of liquidity of $\epsilon c_{1}^{H}(0)$. Define buffer the value that banks can raise by liquidating the long asset while leaving enough resources to pay late consumers in date 2 . For given number of early consumers $\omega$, the buffer then is:

$$
f^{i}(\omega)=r\left[Y^{i}-\left(\mu^{i}-\omega\right) \sum_{\theta} \frac{c_{2}^{i}(\theta)}{\hat{R}^{i}}\right]
$$

where $Y^{i}$ is again the holding of the long asset, and $c_{2}^{i}(\theta)$ is the amount of consumption promised for date 2 as defined in the contract, which is discounted at rate $\hat{R}^{i}$. Clearly, banks in $\mathrm{H}$ are bankrupt if the buffer is not enough to pay for the extra liquidity demand, that is:

$$
\epsilon c_{1}^{H}(0)>f\left(\pi^{H}(0)+\epsilon\right)
$$

If the condition (29) is satisfied, banks are forced to close down, liquidate all their assets and share the proceedings with all their depositors, both domestic and foreign. Assume that banks in F promised $c_{1}^{F}(0)$ to their local early consumers (whose measure is $\pi^{F}(0)$ ), and that in order to fulfill their obligations they made a short-term deposit in banks in $\mathrm{H}$. Then the proceedings from liquidation, defined as $q^{H}$, come from the complete clearing of the budget in H's banks:

$$
X^{H}+r Y^{H}=q^{H}\left(\mu^{H}+\pi^{F}(0)\right)
$$

where $X^{H}$ represents the total holdings of the short asset. The balance budget in (30) states that at bankruptcy total resources are the sum of short asset holdings and the liquidation value of the long asset, and that banks in $\mathrm{H}$ share that amount between $\mu^{H}$ local depositors and $\pi^{F}(0)$ foreign deposits. Rearranging:

$$
q^{H}=\frac{X^{H}+r Y^{H}}{\mu^{H}+\pi^{F}(0)}
$$

What happens to banks in $\mathrm{F}$ is then straightforward: they promised $c_{1}^{F}(0)$ to $\pi^{F}(0)$ agents, but in case of bankruptcy in $\mathrm{H}$ they only receive $q^{H}$. Hence they declare default if:

$$
\pi^{F}(0)\left(c_{1}^{F}(0)-q^{H}\right)>f\left(\pi^{F}(0)\right)
$$


This last expression means that banks in F suffer from contagion if their buffers are not enough to cover for the loss in consumption goods due to bankruptcy in country H. Allen and Gale (2000) formally prove that conditions (29) and (32) are sufficient for an intrinsic shock to generate default in country $\mathrm{H}$ and contagion to country $\mathrm{F}$, respectively.

In what follows, I check whether the presence of hidden savings affects the probability of default and contagion, and how that is in turn affected by the structure of the interbank market.

\subsection{Autarky with Domestic Hidden Markets}

In section 4.1 I showed that when countries are in complete autarky, in the sense that they have no cross-country relationships with each other, the equilibrium consumption allocation is highly inefficient: banks are not able to provide consumption insurance over the amount agents would get if no banks were present. Moreover, I showed that the portfolio allocation emerging in equilibrium is highly inefficient, as banks do not invest enough in liquid assets. Such inefficiency is reflected in the resilience of the system to unexpected perturbations. When the state $\bar{S}$ is realized, the total extra demand for liquidity faced by banks in $\mathrm{H}$ is $\epsilon c_{1}^{H}(0)=\epsilon$, while the total available buffer is only equal to $r \epsilon$. That means in the current environment banks in $\mathrm{H}$ go bankrupt when hit by unexpected shocks. This happens despite the fact that banks in equilibrium invest too much in the long asset: the reason for such result indeed lies in the fact that banks are forced by incentive compatibility to entitle late consumers with too much consumption.

What about contagion? Given that there are no international connections between the two countries, banks in $\mathrm{F}$ do not suffer from the default in $\mathrm{H}$. There is no contagion.

\subsection{Autarky with International Hidden Markets}

The analysis of section 4.2 showed that in an autarkic equilibrium the presence of crosssectoral hidden borrowing and lending makes banks specialize their investment strategies in the asset for which they enjoy a comparative advantage. That means banks in country $\mathrm{H}$ only hold short assets, banks in $\mathrm{F}$ only hold long assets, and depositors in both countries trade in the shadow market: late consumers in $\mathrm{H}$ lend, and early consumers in $\mathrm{F}$ borrow.

What happens when I perturb the equilibrium via the realization of the state $\bar{S}$ ? Banks in $\mathrm{H}$ now face a higher number of early consumers and a correspondingly lower number of late consumers, but they invested all their deposits in short asset anyway, hence no 
bankruptcy is started: banks in $\mathrm{H}$ are solvent. Similarly, also banks in F are perfectly solvent, as there is no contagion.

The fact that there are neither bankruptcy nor contagion does not mean that the unforeseen liquidity need does not have any effect in this economy. In fact, it does influence the ex post allocation of resources, in particular among those agents who rely on the shadow market to fulfill their consumption. To see this, notice that at $\bar{S}$ the return on the shadow market spikes up, as $R^{A}=\frac{\pi^{F}(0)}{\pi^{H}(1)-\epsilon} \hat{R}^{F}>\frac{\pi^{F}(0)}{\pi^{H}(1)} \hat{R}^{F}$. This in turn affects the distribution of income between late consumers in country $\mathrm{H}$ (lenders) and early consumers in country $\mathrm{F}$ (borrowers). To be more specific, the first ones enjoy a higher return on their lending, and are therefore better off, while the second ones pay a higher return on their borrowing, so they lose from the unexpected unfavorable state.

\subsection{Liberalized Economy with International Hidden Markets}

In section $4.3 \mathrm{I}$ showed that in an equilibrium with free interbank markets intermediaries make cross-country deposits in order to exploit regulatory comparative advantages and consequent gains from financial integration. In this way, banks provide perfect cross-country risk sharing. At the same time, I also proved that the presence of hidden savings still limits intertemporal risk sharing.

The analysis of this case is similar the one for complete autarky. By plugging the equilibrium allocation into (29), it is easy to see that the unexpected realization of state $\bar{S}$ always leads to bankruptcy in country $\mathrm{H}$, because:

$$
\epsilon>f^{H}\left(\pi^{H}(0)+\epsilon\right)=r \epsilon
$$

that is, the extra liquidity need is bigger than the available buffer. If that is the case, the amount of resources intermediaries are able to transfer to their depositors, as characterized by (31), is:

$$
q^{H}=\frac{r \mu^{H}+(1-r) \pi^{H}(0)}{\mu^{H}+\pi^{F}(0)}
$$

which is clearly less than one because the numerator is a linear combination of $\mu^{H}$ and $\pi^{H}(0)<\mu^{H}$, while the denominator is bigger than $\mu^{H}$.

What happens to intermediaries in country F? Notice that the available buffer $f^{F}\left(\pi^{F}(0)\right)$ is actually zero, and that they have to cover for the loss of their investments in sector $\mathrm{H}$. 
Condition (32) is therefore satisfied:

$$
\pi^{F}(0)\left(1-q_{I}^{H}\right)>f^{F}\left(\pi^{F}(0)\right)=0
$$

The appearance of state $\bar{S}$ then always leads to contagion, too. The intuition for this result is straightforward: as I pointed out earlier, the presence of hidden savings imposes a burden on the amount of risk sharing that banks can provide. In particular, banks are not able to optimally compress the ex post income profile of their customers as the planner does, and offer too much consumption to late consumers. As a consequence, the investment in liquidity in this environment are always sub-optimal, and the available buffer always not enough, leading to generalized default.

\subsection{Regulated Equilibrium}

As a last case, I analyze the stability of the financial system to intrinsic shocks when the socially optimal allocation is implemented. This is an important comparison, because I prove in Appendix $\mathrm{C}$ that there exist a simple regulatory intervention in the form of an liquidity-to-capital ratio that implements the efficient allocation in both autarky and integrated equilibrium. Therefore, this third case is equivalent to the analysis of an optimally regulated economy.

Then the question I want to ask is the following: can regulation improve the resilience of integrated competitive equilibrium? In order to answer this question, I apply the same methodology of the previous subsections to the constrained efficient allocation. The extra amount of liquidity needed by banks in $\mathrm{H}$ is $\epsilon \mathcal{I}^{*}$. On the other side, notice that the investment in long asset induced by regulation is $Y^{H *}=\pi^{H}(1) R^{*} \mathcal{I}^{*} / \hat{R}^{F}$, hence the total available buffer is $r \in R^{*} \mathcal{I}^{*} / \hat{R}^{F}$. Clearly, since I proved in section 3 that $R^{*} \mathcal{I}^{*}<\hat{R}^{F}$, the buffer is not enough to cover for any unexpected liquidity need, hence banks in $\mathrm{H}$ go bankrupt even in presence of optimal regulation. The intuition for this result lies in the fact that optimal regulation pushes banks on one side to hold more liquidity, but on the other to promise a higher amount of consumption good to the early consumers. Thus, when an unexpected shock is realized banks end up with a higher liquidity need and a lower buffer than they would have with no regulation at all.

The value of the consumption bundle banks in $\mathrm{H}$ provide at default can be derived from (31) by noticing that the investment in short asset induced by optimal regulation is 
$X^{H *}=\pi^{H}(0) \mathcal{I}^{*}$. Therefore:

$$
q^{H}=\frac{\mathcal{I}^{*}\left[r \frac{R^{*}}{\hat{R}^{F}} \mu^{H}+\left(1-r \frac{R^{*}}{\hat{R}^{F}}\right) \pi^{H}(0)\right]}{\mu^{H}+\pi^{F}(0)}<\mathcal{I}^{*}
$$

Then the amount of extra liquidity needed by banks in $\mathrm{F}$ is $\pi^{F}(0)\left(\mathcal{I}^{*}-q^{H}\right)>0$, but again the buffer is equal to zero, hence there is contagion. Optimal regulation does not improve the resilience of an integrated financial system to unexpected perturbations.

\subsection{Summary}

The results of this sections are complementary to those of the previous one. Were the economy divided into autarkic regions, I prove that international shadow markets would distort the optimal allocation of consumption towards late consumption, and push banks to specialize their investment strategies. That in turn is beneficial for the resilience of the financial system, that always have enough resources to cover for extra liquidity needs. As I stressed before, that does not come at no cost, though: unexpected liquidity shocks would still produce winners and losers from the redistribution of resources via the hidden market.

When the interbank market is opened, the positive stabilizing effect of hidden markets instead disappears, as banks in $\mathrm{H}$ do trade with banks in $\mathrm{F}$ and therefore do not specialize in liquid assets. Therefore, banks always go bankrupt, and there is always contagion. The introduction of optimal regulation, to overcome the inefficient allocation of resources in competitive equilibrium, in fact does not positively affect the instability of the system, as banks are forced to hold less long assets and therefore lower their buffer. Again, the role of hidden markets in inducing financial contagion then crucially depends on the underlying structure of the interbank market.

\section{Some Historical Background}

The results from the previous sections have some important parallels with the debate about the so called "Savings \& Loan Debacle".

Savings and Loan Associations (also S\&Ls) are financial institutions whose main activity is the provision of savings accounts and residential mortgages. In 1966, a period of profound financial turbulence close to the collapse of the Bretton Woods System, U.S. Congress passed the Interest Rate Adjustment Act (also known as "Regulation Q") with 
the aim of strictly regulating banking activities. In particular, S\&Ls were on one side restricted to offer only savings accounts, and on the other allowed to pay as interest only 50 basis points more than that offered by commercial banks. ${ }^{9}$ In that way, the administration thought of preserving the social role of such associations in the supply of home mortgages. ${ }^{10}$ Nevertheless, such constraints soon became a burden on S\&Ls, as many customers withdrew their deposits in order to invest in other instruments, such as money market funds, that at the time provided higher yields. Such a phenomenon became known as "disintermediation", and resembles the mechanism underlying the autarky equilibrium with international hidden markets that I showed in section 4.2: banks specialize in the asset for which they enjoy a comparative advantage, and agents exploit hidden markets to adjust their consumption allocation.

At last, when the interest rates ceilings on deposits were completely removed by the Garn-St. Germain Depository Institutions Act of 1982, S\&Ls were allowed to raise interest rates in order to increase their profitability. Such deregulation is easily comparable to a switch from the autarkic equilibrium to the liberalized equilibrium proposed in section 4.3.

The main parallel between the history of S\&Ls and the present model lies in the timing of bankruptcy that affected those institutions between the Eighties and the beginning of the Nineties, and spread out to the whole U.S. financial system, as I show in figure 1. Remember the conclusion from the previous section: first, in a autarkic equilibrium with cross-sectoral hidden markets bankruptcy never happens; second, in an integrated equilibrium unexpected shocks to fundamentals always lead to bank defaults and contagion. That may give an explanation to what happened in the American financial system at that time, too: in the Seventies - a period characterized by extreme financial instability - the rigidly separated system, although inefficient, may have provided a way to avoid generalized bankruptcy in the banking sector. The introduction of looser limitations at the beginning of the Eighties, with the clear aim of increasing profitability and ensure a better risk sharing, may instead have had as a side effect a lower resilience of the system to financial shocks.

\section{Conclusion}

The main question I address in the present paper is: what is the role of unobservable borrowing and lending in affecting liberalization and contagion in the financial system?

\footnotetext{
${ }^{9}$ Interest rates for commercial banks were centrally fixed, too.

${ }^{10}$ More details are available in the extensive book by White (1991) and in the publications by FDIC (1997).
} 
I showed that the answer crucially depends on the openness of the underlying interbank market. In general, hidden markets impose a burden on financial intermediaries, who are not able to improve risk sharing in equilibrium. On the other hand, they might also have a positive effect on the welfare of the economy, if they substitute for the absence of international official markets. Moreover, by inducing specialization in the investment strategy, they might also improve the resilience of the financial system to unexpected liquidity shocks. To put it differently, the effect of hidden markets on financial intermediation is therefore controversial.

This analysis is admittedly incomplete. First of all, it might be useful to extend it to a multicountry environment, in order to study different networks of banks and different channels for contagion. More importantly, here intermediaries have no way to predict future shocks, and eventually insure against unexpected liquidity needs. Therefore, a more complete environment should formally introduce aggregate uncertainty and markets for state-contingent claims, that banks can use to share risks. This is the way I am currently seeking in a companion paper (Panetti, 2011). More work is needed in that direction. 


\section{References}

Allen, F. and D. Gale (2000, February). Financial Contagion. Journal of Political Economy 108(1), 1-33.

Allen, F. and D. Gale (2004, July). Financial Intermediaries and Markets. Econometrica 72(4), 1023-1061.

Brusco, S. and F. Castiglionesi (2007, October). Liquidity Coinsurance, Moral Hazard, and Financial Contagion. Journal of Finance 62(5), 2275-2302.

Diamond, D. W. and P. H. Dybvig (1983). Bank Runs, Liquidity and Deposit Insurance. Journal of Political Economy 91, 401-419.

Farhi, E., M. Golosov, and A. Tsyvinski (2009). A Theory of Liquidity and Regulation of Financial Intermediation. Review of Economic Studies 76, 973-992.

FDIC (1997). History of the Eighties - Lessons for the Future. Technical report, Federal Deposit Insurance Corporation.

Golosov, M. and A. Tsyvinski (2007). Optimal Taxation with Endogenous Insurance Markets. Quarterly Journal of Economics 122, 487-534.

Gorton, G. (1988). Banking Panics and Business Cycles. Oxford Economic Papers 40(3), $751-781$.

Imai, M. and S. Takarabe (2011, January). Bank Integration and Transmission of Financial Shocks: Evidence from Japan. American Economic Journal: Macroeconomics 3(1), 155183.

Iyer, R. and J.-L. Peydró (2010, January). Interbank Contagion at Work: Evidence from a Natural Experiment. ECB Working Paper Series No. 1147.

Mediobanca Research Department (2010, November). Public Support Measures in Europe and in the United States. Technical report, Mediobanca Research Department.

Panetti, E. (2011, February). Unobservable Savings, Risk Sharing and Default in the Financial System. mimeo.

Pozsar, Z., T. Adrian, A. Ashcraft, and H. Boesky (2010, July). Shadow Banking. Staff Report 458, Federal Reserve Bank of New York. 
White, L. J. (1991). The SESL debacle: Public policy lessons for bank and thrift regulation. New York: Oxford University Press. 


\section{A Why only bonds in the shadow market?}

I follow the analysis in Golosov and Tsyvinski (2007). Remember that, when borrowing and lending, individual types are still private information. In order to complete the set of traded securities, we may then add claims paying 1 unit of the consumption good conditional on reporting type $\theta$. Define the price of such securities as $Q(\theta)$. Notice that $1 / R$ is the price of a risk-free bond delivering one unit of consumption in the following period for each unit invested today. I can prove the following:

Lemma 6. $Q(\theta) \geq \frac{1}{R}$ for every type $\theta \in\{0,1\}$.

Proof. I prove the lemma by contradiction. Assume $Q\left(\theta^{\prime}\right)<\frac{1}{R}$ for some $\theta^{\prime}$. That would give rise to arbitrage opportunities: agents would buy infinitely many of such securities, sell uncontingent bonds in the same amount, then report exactly type $\theta^{\prime}$, and enjoys infinite utility. That cannot be an equilibrium.

Given that $Q(\theta) \geq \frac{1}{R}$, it is easy to argue that no type-contingent claims will be traded: individuals will never exchange securities which yield one unit of consumption if a specific type is reported, when they have the opportunity to trade a cheaper bond which yields one unit of consumption whatever type is reported.

\section{B Liberalized Economy without Hidden Savings}

In this appendix, I characterize the decentralized equilibrium with integrated interbank markets in absence of the shadow markets for borrowing and lending. I also show that it is constrained efficient, i.e. the allocation of consumption satisfies the conditions for an equilibrium in section 3. In line with the assumption in Diamond and Dybvig (1983), here I still assume that individual types are private information, hence banks need to impose incentive compatibility in writing the deposit contract. Therefore, in what follows the only difference from the problems defined in section 4.3 is that the incentive compatibility constraint now reads:

$$
U\left(C^{i}(\theta), \theta\right) \geq U\left(C^{i}\left(\theta^{\prime}\right), \theta\right)
$$

for every $\theta, \theta^{\prime} \in\{0,1\}$. This means no agent has incentive to wrongfully report her type. I can prove the following result:

Lemma 7. The integrated equilibrium with no shadow markets is constrained efficient. 
Proof. Given that the system is integrated, banks in $\mathrm{H}$ will invest in F's long asset by making an interbank deposit. Banks then solve:

$$
\max _{c_{1}^{i}(\theta), c_{2}^{i}(\theta)} \quad \sum_{\theta} U\left(C^{i}(\theta), \theta\right)
$$

subject to the resource constraint in (24) and the incentive compatibility in (37). Guess the incentive compatibility constraint is slack. Attach multiplier $\lambda$ to the resource constraint. The first order conditions with respect to $c_{1}^{i}(0)$ and $c_{2}^{i}(1)$ are respectively:

$$
\begin{aligned}
u^{\prime}\left(c_{1}^{i}(0)\right) & =\lambda \\
\beta \hat{R}^{F} u^{\prime}\left(c_{2}^{i}(1)\right) & =\lambda
\end{aligned}
$$

Therefore an Euler equation regulates the intertemporal allocation between early and late consumers. Moreover, given that banks in every country have the same investment strategy they provide the very same consumption bundle, hence there is perfect cross-country risk sharing, too. Finally, I need to verify that the incentive compatibility is actually slack. This is true if the present discounted value of the consumption bundle received by each type is bigger than the one they might receive if they report incorrectly. This is equivalent to prove the following corollary:

Corollary 1. In an integrated equilibrium without hidden markets $c_{1}^{i}(0)>1$ and $c_{2}^{i}(1)<$ $\hat{R}^{F}$.

Proof. Assume not, i.e. $c_{1}^{i}(0)<1$. Then the resource constraint implies $c_{2}^{i}(1)>\hat{R}^{F}$. From the Euler equation and the fact that relative risk aversion is bigger than or equal to one, ${ }^{11}$ we have:

$$
\beta \hat{R}^{F}=\frac{u^{\prime}\left(c_{1}^{i}(0)\right)}{u^{\prime}\left(c_{2}^{i}(1)\right)} \geq \frac{c_{2}^{i}(1)}{c_{1}^{i}(0)} \geq \hat{R}^{F}
$$

which is impossible because $\beta<1$. This ends the proof.

\footnotetext{
${ }^{11}$ See lemma 11 in Appendix D.
} 


\section{Optimal Regulation}

In section 4, I showed that the main problem of the competitive equilibrium, either with autarkic or integrated markets, stems in a return on the shadow market $R$ that is not efficient. Optimal regulation will then give incentives to banks to act in such a way so that the hidden return is optimal. It may be argued that a competitive equilibrium with a shadow return lower (or higher) than the one emerging from arbitrage actually cannot be an equilibrium by definition (that is exactly the way we proved lemmas 4 and 5), because it would push banks to invest only in the asset with higher yield, and give no resources to some agents. That is the intuition for why optimal regulation takes the form of capital requirements. From a technical point of view, the banking problem looks exactly the same as before, but with the addition of a further constraint. The design problem is then to find the optimal binding constraint that induces banks to provide the efficient allocation.

\section{C.1 Autarky with International Hidden Markets}

Given that $\hat{R}^{F}>\hat{R}^{H}>1$, in order to fully characterize optimal regulation I need to take into account two different cases.

Case 1: $\mathbf{R}^{\mathbf{H}}>\hat{\mathbf{R}}^{*}$. Here the efficient return on the shadow market is so low (relative risk aversion is so high) that banks in both sectors would find convenient to invest only in their long assets, had they to face such hidden return. Therefore, in order for that to be an equilibrium, we need to impose a liquidity floor, i.e. a minimum capital requirement, on both sectors, so that banks have enough (actually, the optimal amount of) resources to provide consumption to depositors in early liquidity need. The capital requirement constraint reads:

$$
\sum_{\theta} \pi^{i}(\theta) c_{1}^{i}(\theta) \geq F^{i} \mu^{i}
$$

where $F^{i}$ is the capital requirement, expressed as total investment in the short asset as a percentage of total capital.

Case 2: $\hat{\mathbf{R}}^{\mathbf{F}}>\mathbf{R}^{*}>\hat{\mathbf{R}}^{\mathbf{H}}$. Here the efficient return on the shadow market is high enough (relative risk aversion is low enough) that banks in $\mathrm{H}(\mathrm{F})$ will still find convenient to invest only in the short(long) asset. Therefore, in order for that to be an equilibrium, I need to impose the correct liquidity ceiling to banks in $\mathrm{H}$ (lower than 100 percent), and the correct 
liquidity floor to banks in F (bigger than zero). Formally, it must be the case that:

$$
\sum_{\theta} \pi^{i}(\theta) c_{1}^{i}(\theta) \begin{cases}\leq F^{i} \mu^{i} & i=H \\ \geq F^{i} \mu^{i} & i=F\end{cases}
$$

The banking problem is therefore defined as the maximization of (11), subject to incentive compatibility (3), the budget constraint (12) and the capital requirement defined by either (40) or (41). The following can be proved:

Lemma 8. With autarkic markets, the optimal capital requirement $F^{i}$ in each sector $i \in$ $\{H, F\}$ is:

$$
F^{i}=\frac{\pi^{i}(0) \mathcal{I}^{*}}{\mu^{i}}
$$

According to the country, such requirement is a liquidity floor or a ceiling.

Proof. In the following.

\section{C.2 Liberalized Economy with International Hidden Markets}

Remember that in the case of integrated equilibrium banks are allowed to invest one into each other via the interbank market. As a consequence, I showed that banks in both sectors will invest in H's short asset and F's long asset. Nevertheless, inefficiency arises because the return on the shadow market is too high, leading to a sub-optimal portfolio allocation. In order to have a hidden return lower than $\hat{R}^{F}$ as a decentralized market outcome, we then need to impose on every bank a minimum capital requirement similar to the one in (40), otherwise with $R<\hat{R}^{F}$ every bank would exclusively invest in the long asset. It comes out that, despite the underlying differences between the two cases, optimal regulation in an integrated economy is similar to the one in autarky:

Lemma 9. With integrated markets, the optimal capital requirement $F^{i}$ in each sector $i \in\{H, F\}$ takes the form of a liquidity floor:

$$
F^{i}=\frac{\pi^{i}(0) \mathcal{I}^{*}}{\mu^{i}}
$$

Proof. I solve for case $2\left(\hat{R}^{F}>R^{*}<\hat{R}^{H}\right)$ in sector $\mathrm{H}$ in the autarkic equilibrium, as the 
other cases have similar proofs. The regulated banking problem is:

$$
\max _{\left\{C^{H}(\theta)\right\}_{\theta \in\{0,1\}}} \pi^{H}(0) u\left(c_{1}^{H}(0)+\frac{c_{2}^{H}(0)}{R}\right)+\beta \pi^{H}(1) u\left(R c_{1}^{H}(1)+c_{2}^{H}(1)\right)
$$

subject to:

$$
\begin{aligned}
\sum_{\theta} \pi^{H}(\theta)\left[c_{1}^{H}(\theta)+\frac{c_{2}^{H}(\theta)}{\hat{R}^{H}}\right] & \leq \mu^{H} \\
c_{1}^{H}(0)+\frac{c_{2}^{H}(0)}{R} & =c_{1}^{H}(1)+\frac{c_{2}^{H}(1)}{R} \\
\pi^{H}(0) c_{1}^{H}(0)+\pi^{H}(1) c_{1}^{H}(1) & \leq F^{H} \mu^{H}
\end{aligned}
$$

Apply the following change of variable:

$$
\begin{aligned}
\mathbb{I}^{H} & =c_{1}^{H}(0)+\frac{c_{2}^{H}(0)}{R} \\
\mathbb{H}^{H} & =\frac{1}{\mu^{H}}\left[\pi^{H}(0) c_{1}^{H}(0)+\pi^{H}(1) c_{1}^{H}(1)\right]
\end{aligned}
$$

so that the problem now reads:

$$
\max _{\mathbb{I}^{H}, \mathbb{H}^{H}} \pi^{H}(0) u\left(\mathbb{I}^{H}\right)+\beta \pi^{H}(1) u\left(R \mathbb{I}^{H}\right)
$$

subject to:

$$
\begin{aligned}
\mathbb{I}^{H}-\mathbb{H}^{H}\left(\frac{1}{R}-\frac{1}{\hat{R}^{H}}\right) & \leq 1 \\
\mathbb{I}^{H}-\frac{\mathbb{H}^{H}}{R} & \leq F^{H}
\end{aligned}
$$

Attach multipliers $\xi$ and $\lambda$, respectively. The first order conditions are:

$$
\begin{array}{cl}
\mathbb{I}^{H}: & \pi^{H}(0) u^{\prime}\left(\mathbb{I}^{H}\right)+\beta R \pi^{H}(1) u^{\prime}\left(R \mathbb{I}^{H}\right)=\lambda+\xi \\
\mathbb{H}^{H}: & \frac{\lambda}{R}+\xi\left(\frac{1}{R}-\frac{1}{\hat{R}^{H}}\right)=0
\end{array}
$$


Plug (45) into (44) and derive:

$$
\xi=\frac{\hat{R}^{H}}{R}\left[\pi^{H}(0) u^{\prime}\left(\mathbb{I}^{H}\right)+\beta R \pi^{H}(1) u^{\prime}\left(R \mathbb{I}^{H}\right)\right]
$$

which is nonnegative because of the assumption of concavity of the felicity function. We want to derive the capital requirement $F^{H}$ which is consistent with the implementation of the efficient allocation. Substitute the latter in the characterization of the equilibrium:

$$
\begin{aligned}
R & =R^{*} \\
\mathbb{I}^{H} & =\mathcal{I}^{H} \\
\mathbb{H}^{H} & =\frac{1}{\mu^{H}} \pi^{H}(1) R^{*} \mathcal{I}^{H}
\end{aligned}
$$

From (45), given that $\hat{R}^{H}<R^{*}$, we have that also $\lambda>0$ : the liquidity ceiling is binding. At last, by plugging the efficient allocation in (43) we derive the solution to $F^{H}$.

In all cases, the capital requirement takes the form of an liquidity-to-capital ratio: in order for the decentralized equilibrium to implement the efficient allocation, banks are indeed forced to invest a specific amount of their total deposits into short assets. Depending on relative risk aversion (which affects efficient pricing), the technology available to each sector and the interbank market structure, the previous lemmas show that such obligation is enforced through a liquidity floor or ceiling. The modified portfolio allocation is exactly enough to provide to all early consumers the efficient amount of consumption.

\section{Proofs}

Proof of lemma 1. Rewrite the problem of the agent in the shadow market as:

$$
\begin{aligned}
V\left(C^{i}(\theta), R, \theta\right)= & \max _{x_{1}^{i}, x_{2}^{i}, b^{i}, \theta^{\prime}} U\left(x_{1}^{i}, x_{2}^{i}, \theta\right) \\
\text { s.t. } & x_{1}^{i}+\frac{x_{2}}{R}=c_{1}^{i}\left(\theta^{\prime}\right)+\frac{c_{2}^{i}\left(\theta^{\prime}\right)}{R}
\end{aligned}
$$

For type 1 and 2, the incentive compatibility then respectively reads:

$$
\begin{aligned}
& V\left(C^{i}(0), R, 0\right) \geq V\left(C^{i}(1), R, 0\right) \\
& V\left(C^{i}(1), R, 1\right) \geq V\left(C^{i}(0), R, 1\right)
\end{aligned}
$$


which can be rewritten as:

$$
\begin{aligned}
& u\left(c_{1}^{i}(0)+\frac{c_{2}^{i}(0)}{R}\right) \geq u\left(c_{1}^{i}(1)+\frac{c_{2}^{i}(1)}{R}\right) \\
& u\left(R c_{1}^{i}(1)+c_{2}^{i}(1)\right) \geq u\left(R c_{1}^{i}(0)+c_{2}^{i}(0)\right)
\end{aligned}
$$

The result then follows.

Proof of Lemma 2. The definition of the constrained efficient allocation is standard:

Definition 3. Given an initial endowment $e$ for any agent and a distribution of idiosyncratic shocks $\left\{\pi^{i}(\theta)\right\}$, a constrained efficient allocation with shadow markets is a contract $\left\{C^{i}(\theta)\right\}$ for any type and country and a portfolio choice $\left\{X, Y^{H}, Y^{F}\right\}$ such that:

- The contract and the portfolio choice solve the planning problem

- Resources are exhausted:

$$
\sum_{i} \sum_{\theta} \pi^{i}(\theta)\left[c_{1}^{i}(\theta)+\frac{c_{2}^{i}(\theta)}{\hat{R}^{B}}\right]=1
$$

In order to prove the lemma, I want to first reduce the dimentionality of the problem. I can do this using the following result:

Lemma 10. Problem (4) is equivalent to:

$$
\max _{R,\left\{\mathcal{I}^{i}\right\}_{i \in\{A, B\}}} \sum_{i} \sum_{\theta} \pi^{i}(\theta) \tilde{V}\left(\mathcal{I}^{i}, R, \theta\right)
$$

subject to:

$$
\sum_{i} \sum_{\theta} \pi^{i}(\theta)\left[x_{1}^{i}\left(\mathcal{I}^{i}, R, \theta\right)+\frac{x_{2}^{i}\left(\mathcal{I}^{i}, R, \theta\right)}{\hat{R}^{B}}\right] \leq 1
$$

where $\tilde{V}, x_{1}^{i}$ and $x_{2}^{i}$ come from the solution to:

$$
\begin{array}{ll}
\tilde{V}\left(\mathcal{I}^{i}, R, \theta\right)= & \max _{x_{1}^{i}, x_{2}^{i}} U\left(x_{1}^{i}, x_{2}^{i}, \theta\right) \\
\text { s.t. } & x_{1}^{i}+\frac{x_{2}^{i}}{R} \leq \mathcal{I}^{i}
\end{array}
$$

Proof. In order to prove that (4) and (48) are equivalent, I need to show that the allocation that solves the first can be implemented for some $\left\{R, \mathcal{I}^{i}\right\}$ satisfying (48), and that 
given $\left\{R^{*}, \mathcal{I}^{i *}\right\}$ solution to (48), we can set $c_{t}^{i}(\theta)=x_{t}^{i}\left(\mathcal{I}^{i}, R, \theta\right)$ in (4) and check that such allocation is feasible.

Take any $\left\{c_{t}^{i}(\theta)\right\}$ solution to (4). By definition, such allocation satisfies incentive compatibility $c_{1}^{i}(0)+\frac{c_{2}^{i}(0)}{R}=c_{1}^{i}(1)+\frac{c_{2}^{i}(1)}{R}$. Call this present discounted value $\mathcal{I}^{i}$. Notice that $\left\{c_{t}^{i}(\theta)\right\}$ is solution to the hidden problem (1) with equilibrium return $R$, hence it also solves (50) provided $\theta^{\prime}=\theta$, i.e. the true type is reported. This means that any solution to (4) can be implemented with the correct choice of $\left\{R, \mathcal{I}^{i}\right\}$. This ends the first part of the proof.

Let us move to the second part. Assume $\left\{R^{*}, \mathcal{I}^{i *}\right\}$ is solution to (48). Pick $c_{t}^{i}(\theta)=$ $x_{t}^{i}\left(\mathcal{I}^{i}, R, \theta\right)$. Clearly, the resource constraints are equivalent. Moreover, notice that:

$$
\mathcal{I}^{i *}=c_{1}^{i}(0)+\frac{c_{2}^{i}(0)}{R}=c_{1}^{i}(1)+\frac{c_{2}^{i}(1)}{R}
$$

meaning that $\tilde{V}\left(\mathcal{I}^{i}, R, \theta\right)=V\left(C^{i}(\theta), R, \theta\right)$, because with income $\mathcal{I}^{i *}$ every agent does as well by reporting the true type or the other. Given that $\left\{x_{t}^{i}\right\}$ solves (50), it must be the case that $U\left(c_{1}^{i}(\theta), c_{2}^{i}(\theta), \theta\right) \geq V\left(C^{i}(\theta), R, \theta\right)$, hence also incentive compatibility (6) is satisfied. This ends the proof.

Hence, I can solve (48) instead of (4). I do it by backward induction. For $\theta=0$, the program in (50) reads:

$$
\begin{array}{ll}
\max & u\left(x_{1}^{i}\right) \\
\text { s.t. } & x_{1}^{i}+\frac{x_{2}^{i}}{R} \leq \mathcal{I}^{i}
\end{array}
$$

Clearly, $x_{1}^{i}\left(\mathcal{I}^{i}, R, 0\right)=\mathcal{I}^{i *}$, and in a similar fashion $x_{2}^{i}\left(\mathcal{I}^{i}, R, 1\right)=R \mathcal{I}^{i *}$. Plug these results back, program (48) can be rewritten as:

$$
\max _{R,\left\{\mathcal{I}^{i}\right\}_{i \in\{H, F\}}} \sum_{i} \pi^{i}(0) u\left(\mathcal{I}^{i *}\right)+\beta \pi^{i}(1) u\left(R \mathcal{I}^{i *}\right)
$$

subject to:

$$
\sum_{i} \mathcal{I}^{i *}\left[\pi^{i}(0)+\pi^{i}(1) \frac{R}{\hat{R}^{F}}\right] \leq 1
$$


Attach multiplier $\lambda$ to (54) and take first order conditions:

$$
\begin{array}{ll}
\mathcal{I}^{i}: & \pi^{i}(0) u^{\prime}\left(\mathcal{I}^{i}\right)+\beta \pi^{i}(1) u^{\prime}\left(R \mathcal{I}^{i}\right) R=\lambda\left[\pi^{i}(0)+\pi^{i}(1) \frac{R}{\hat{R}^{F}}\right] \\
R: & \beta \sum_{i} \pi^{i}(1) u^{\prime}\left(R \mathcal{I}^{i}\right) \mathcal{I}^{i}=\frac{\lambda}{\hat{R}^{F}} \sum_{i} \pi^{i}(1) \mathcal{I}^{i}
\end{array}
$$

Multiply both sides of (55) by $\mathcal{I}^{i}$ and sum across $i$. Using (56) this becomes:

$$
\lambda=\frac{\sum_{i} \pi^{i}(0) u^{\prime}\left(\mathcal{I}^{i}\right) \mathcal{I}^{i}}{\sum_{i} \pi^{i}(0) \mathcal{I}^{i}}>0
$$

Using (57) into (56):

$$
\beta \hat{R}^{F} \sum_{i} \pi^{i}(1) u^{\prime}\left(R \mathcal{I}^{i}\right) \mathcal{I}^{i}=\frac{\sum_{i} \pi^{i}(0) u^{\prime}\left(\mathcal{I}^{i}\right) \mathcal{I}^{i}}{\sum_{i} \pi^{i}(0) \mathcal{I}^{i}} \sum_{i} \pi^{i}(1) \mathcal{I}^{i}
$$

It is easy to check that (58) is satisfied when the (unconstrained) efficient allocation in (8) is plugged in.

In order to characterize $R^{*}$ as in (9), I need the following lemma:

Lemma 11. If relative risk aversion is greater than 1 , then for any $z_{1}$ and $z_{2}$ :

$$
\frac{u^{\prime}\left(z_{1}\right)}{u^{\prime}\left(z_{2}\right)} \geq \frac{z_{2}}{z_{1}}
$$

Proof. Rewrite the assumption about RRA as as:

$$
-\frac{u^{\prime \prime}(c)}{u^{\prime}(c)} \geq \frac{1}{c}
$$

Hence:

$$
-\left(\log \left[u^{\prime}(c)\right]\right)^{\prime} \geq(\log [c])^{\prime}
$$

Integrate (61) between $z_{1}$ and $z_{2}$ so as to obtain:

$$
\log \left[u^{\prime}\left(z_{1}\right)\right]-\log \left[u^{\prime}\left(z_{2}\right)\right] \geq \log \left[z_{2}\right]-\log \left[z_{1}\right]
$$

The latter gives (59) once taken the exponent.

Using the result in lemma 11, the Euler equation characterizing the efficient allocation 
gives:

$$
\beta \hat{R}^{F}=\frac{u^{\prime}\left(\mathcal{I}^{*}\right)}{u^{\prime}\left(R^{*} \mathcal{I}^{*}\right)} \geq R^{*}
$$

In order to prove that $R^{*}>1$, define:

$$
f(R)=\frac{u^{\prime}\left(\mathcal{I}^{*}\right)}{u^{\prime}\left(R \mathcal{I}^{*}\right)}-\beta \hat{R}^{F}
$$

Notice that $R^{*}$ is the value that sets $f\left(R^{*}\right)=0$. Clearly, this function is everywhere increasing in $\mathrm{R}$, and $f(1)=1-\beta \hat{R}^{F}<0$ by hypothesis, hence it must be the case that $R^{*}>1$.

Given that $\mathcal{I}^{*}$ is equal across sectors, the resource constraint gives:

$$
\mathcal{I}^{*}=\frac{1}{\sum_{i} \pi^{i}(0)+\pi^{i}(1) R^{*}}
$$

which is bigger than 1 because $R^{*}<\hat{R}^{F}$. To see that $c_{2}(1)<\hat{R}^{F}$, notice that we can rewrite the resource constraint as:

$$
\frac{c_{2}(1, s)}{\hat{R}(s)}=\frac{1-\sum_{i} \pi^{i}(0) c_{1}(0)}{1-\sum_{i} \pi^{i}(0)}<1
$$

At this allocation, no agent invests in the hidden market, because incentive compatibility is satisfied and $c_{1}^{i}(1, s)=c_{2}^{i}(0, s)=0$. Finally, the derivation of the optimal total investment in the short asset is trivial, once we plug $c_{1}^{i}(\theta)=\mathcal{I}^{*}$.

Proof of Proposition 2. We take $R$ as given, solve the banking problem in both countries, then by market clearing characterize $R$. The optimal contract in country $\mathrm{H}$ is the solution to the following program:

$$
\max _{\left\{c_{1}^{H}(\theta), c_{2}^{H}(\theta)\right\}_{\theta \in\{0,1\}}} \pi^{H}(0) u\left(c_{1}^{H}(0)\right)+\beta \pi^{H}(1) u\left(R c_{1}^{H}(1)\right)
$$

subject to:

$$
\begin{aligned}
& \sum_{\theta} \pi^{H}(\theta)\left[c_{1}^{H}(\theta)+\frac{c_{2}^{H}(\theta)}{\hat{R}^{H}}\right] \leq \mu^{H} \\
& c_{1}^{H}(0)+\frac{c_{2}^{H}(0)}{R}=c_{1}^{H}(1)+\frac{c_{2}^{H}(1)}{R}
\end{aligned}
$$

Given that banks in country H only invest in the short technology, $c_{2}^{H}(0)=c_{2}^{H}(1)=0$, and 
by incentive compatibility:

$$
c_{1}^{H}(0)=c_{1}^{H}(1)
$$

On the other side, given that banks in $\mathrm{F}$ only invest in long technology, $c_{1}^{F}(0)=c_{1}^{F}(1)=0$, and by incentive compatibility $c_{2}^{F}(0)=c_{2}^{F}(1)$. By market clearing in the bond market in (19), this means:

$$
c_{2}^{F}(0)=c_{2}^{F}(1)=\frac{\pi^{A}(1)}{\pi^{F}(0)} c_{1}^{A}(1) R
$$

Using (68) and (69) in the resource constraint of the economy, and keeping in mind that $\pi^{i}(0)+\pi^{i}(1)=\mu^{i}$, we obtain:

$$
c_{1}^{H}(0)=c_{1}^{H}(1)=\frac{1}{\mu^{H}+\mu^{F} \frac{\pi^{H}(1)}{\pi^{F}(0)} \frac{R}{\hat{R}^{F}}}
$$

It is then easy to show that the proposed allocation solves the program and, together with the market clearing condition for bonds, induces $R^{A}$. As a last step, we need to ensure that the budget constraints are not slack. Notice that the Lagrange multiplier on H's budget $\lambda$ is equal to $u^{\prime}\left(c_{1}^{H}(0)\right)>0$. Similar result applies to $\mathrm{F}$. 


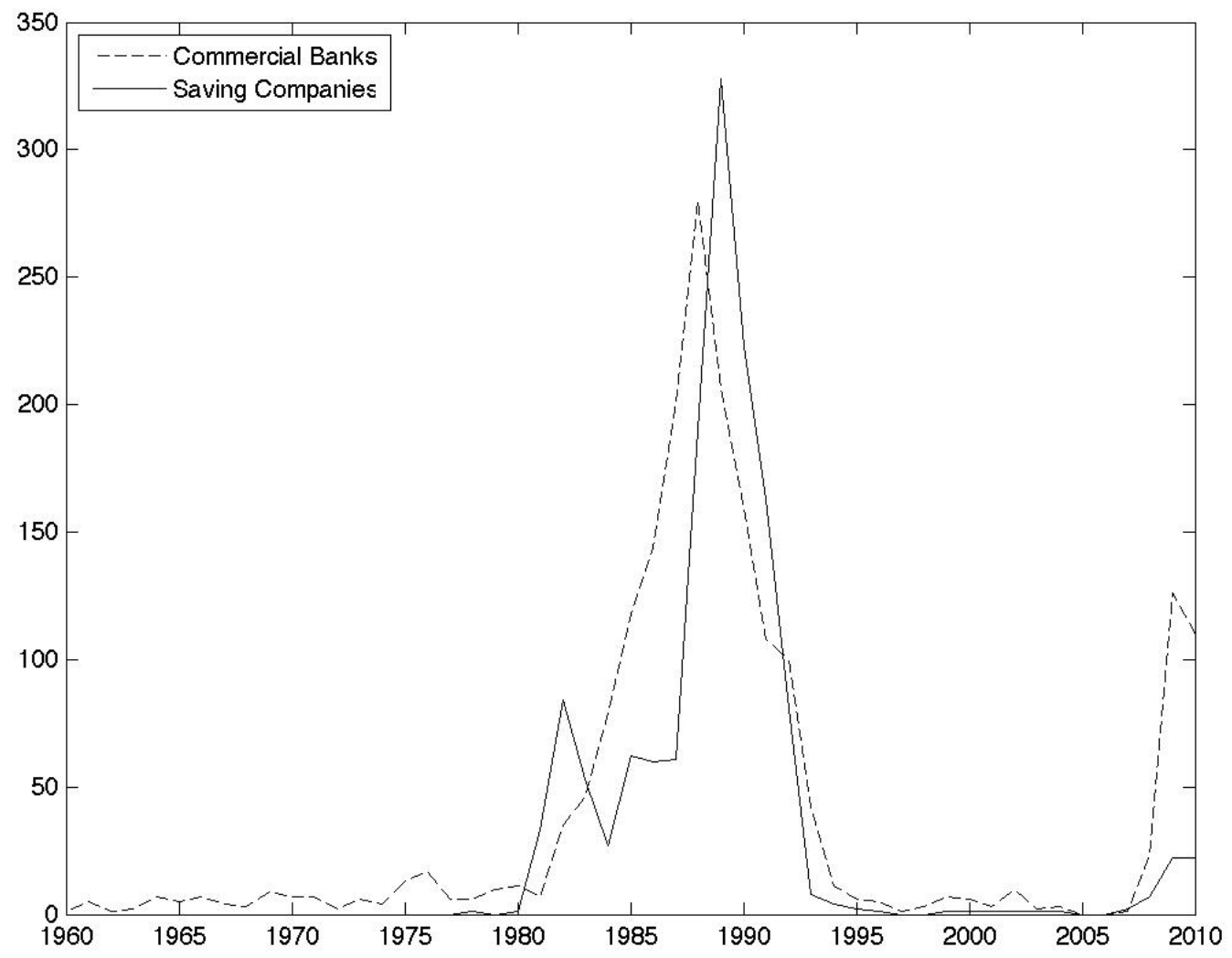

Figure 1: Failures and assistance transactions by the FDIC, 1960-2010. Commercial Banks are defined as (a) National chartered commercial bank supervised by the Office of the Comptroller of the Currency, (b) State charter Fed member commercial bank supervised by the Federal Reserve, and (c) State charter Fed nonmember commercial bank supervised by the FDIC. Saving Companies are defined as: (a) State or federal charter savings association supervised by the Office of Thrift Supervision; (b) State charter savings bank supervised by the FDIC. Source: FDIC, Historical Statistics on Banking. 